\title{
La regulación de los recursos administrativos en el ordenamiento jurídico administrativo peruano
}

\author{
Ronnie Farfán Sousa
}

El profesor Ronnie Farfán analiza
la regulación de los procesos
administrativos en la Ley del
Procedimiento
vigente, Ley 27444 . Parministrativo
desarrolla tanto los fundamentos de
dichos recursos así como sus límites
y clases.

Abogado por la Pontificia Universidad Católica del Perú. Abogado asociado del Estudio Echecopar Abogados, firma asociada a Baker \& McKenzie Internacional. Profesor de Derecho Administrativo de la Universidad del Pacífico y de la Universidad Nacional Mayor de San Marcos. 


\section{Introducción}

Dentro del estudio de los diversos aspectos del procedimiento administrativo, la regulación de los recursos administrativos debiera merecer particular atención si se considera que éstos se configuran como una de las herramientas más relevantes para controlar la legalidad de la actuación administrativa, y al mismo tiempo, para defender los derechos de los administrados que pudieran considerarse afectados por alguna decisión administrativa.

En el caso del ordenamiento jurídico peruano, la Ley del Procedimiento Administrativo General, Ley No. $27444^{1}$, estableció una serie de disposiciones que permiten la correcta articulación de estos dos valores como los fines fundamentales de los recursos administrativos. Del mismo modo, estableció orgánicamente las pautas más importantes que deben regir el trámite de estos recursos buscando también compatibilizar el ejercicio del derecho de defensa propio de los administrados y el principio de seguridad jurídica materializado en la estabilidad de la que deben gozar las actuaciones administrativas.

Sin embargo, como toda norma, ésta cuenta con aspectos aún perfectibles que podrían ser objeto de nueva regulación o, en todo caso, clarificados por el legislador, con el objetivo de dotar a los funcionarios públicos de las herramientas necesarias para actuar y no imponer sobre ellos una responsabilidad interpretativa que muchas veces no se ve desarrollada debido al temor que es capaz de imprimir un mal entendido principio de legalidad.

En el presente trabajo buscaremos delimitar la naturaleza y funciones de los recursos administrativos, nos referiremos a las condiciones y exigencias que regula la normativa administrativa actual para su interposición, analizaremos el trámite que deben seguir y explicaremos las clases de recursos que se han establecido en nuestra legislación general, cuyo ejercicio resulta exigible como paso previo para acudir a la vía judicial. Por lo demás, en algunos casos presentaremos ciertas alternativas que consideramos deberían ser objeto de evaluación con la finalidad de perfeccionar el sistema de recursos administrativos, desde nuestra opinión.

\section{Fundamento y funciones de los recursos administrativos}

Como se sabe, la regulación nacional contempla únicamente dos vías para llevar a cabo la revisión de una decisión administrativa: (i) la revisión de oficio y (ii) la interposición de recursos administrativos. En el primer caso, la revisión de oficio se constituye como una herramienta a través de la cual la Administración, por su propia decisión, puede resolver dar inicio a un procedimiento de revisión de alguna decisión

1 En adelante nos referiremos a esta norma, indistintamente, como la "Ley del Procedimiento Administrativo General", la "LPAG", la "Ley No. 27444" o simplemente "la ley". 
administrativa previamente adoptada, buscando su corrección, su modificación o, simplemente, dejarla sin efectos.

En el segundo caso, en cambio, es el administrado quien solicita a la Administración que revise determinado acto por considerar que éste le causa algún tipo de agravio y que resulta contrario al régimen de legalidad establecido para la adopción de decisiones administrativas. A diferencia del primer supuesto, los recursos administrativos constituyen, entonces, mecanismos de impugnación a través de los cuales los administrados reaccionan ante un acto de la Administración que los perjudica, promoviendo que éste sea dejado sin efectos.

Es posible definir a los recursos administrativos, entonces, como aquellas actuaciones a través de las cuales un sujeto legitimado le solicita a una entidad pública que revise una resolución administrativa, o excepcionalmente un acto de trámite, de acuerdo con las condiciones exigidas por el marco legal vigente, con la finalidad de obtener la anulación o modificación de un acto emitido por la misma entidad.

Tomando estos aspectos en consideración, debemos partir por advertir que la doctrina ha discutido durante mucho tiempo si los recursos administrativos tienen por finalidad convertirse en una garantía de defensa para los administrados o si es que en realidad se trata de un privilegio de la Administración proveniente de su característica autotutela. De acuerdo con la primera posición, los recursos se configuran como un mecanismo para que los administrados puedan cuestionar una decisión que consideran que los agravia y, además, obtener una decisión acorde con su interés en sede administrativa sin la necesidad de verse involucrados en un proceso judicial que importe un mayor gasto de tiempo y recursos.

Quienes se refieren al sistema de recursos administrativos como privilegio de la Administración, en cambio, señalan que no puede soslayarse que la exigencia de interponer recursos administrativos antes de poder recurrir a la vía judicial supone necesariamente una limitación al derecho a la tutela judicial efectiva, el mismo que solo se puede ver realmente satisfecho ante la justicia ordinaria donde existe un verdadero juez imparcial y no a través de la revisión de actos por parte de la misma entidad que emitió la decisión objeto de cuestionamiento.

Esta última posición sirve muchas veces para respaldar una opinión según la cual, en el marco de un Derecho Administrativo moderno que tiene un enfoque garantista sobre el administrado, los recursos administrativos no deberían existir y se debería permitir que el administrado acuda directamente a la sede judicial cuando quiera cuestionar una decisión administrativa. Una posición un poco más moderada ${ }^{2}$ propone que los recursos administrativos tengan carácter potestativo de manera tal que, ante un acto administrativo que consideren contrario a sus intereses, los administrados tengan la

2 Al respecto, puede verse, entre otros: Linde Paniagua, Enrique, Fundamentos de Derecho Administrativo, Cuarta Edición, Colex Editorial, Madrid, 2012, p. 519. 
posibilidad de cuestionar la decisión ante la propia Administración o de acudir directamente al proceso contencioso administrativo en sede judicial.

Desde nuestro punto de vista, no cabe duda de que los recursos administrativos, al menos en el ordenamiento peruano, ofrecen hoy una alternativa nada despreciable para que los administrados puedan cuestionar una decisión que les agravia. Así, frente a los problemas que presenta la justicia ordinaria en nuestro país, estimando la larga duración de los procesos judiciales, la complejidad que supone contar con jueces especializados en cada materia de aquellas que atiende la Administración y los altos costos que supone la asistencia letrada permanente en el desarrollo de un juicio, el procedimiento recursivo se presenta como una alternativa mucho más expeditiva, flexible y menos costosa, lo que realmente se convierte en una garantía para el administrado ${ }^{3}$.

No puede perderse de vista, además, que en algunos casos los costos de un proceso contencioso administrativo pueden ser sorprendentemente desproporcionales frente al objeto del acto administrativo que resulte objeto de cuestionamiento. Piénsese, por ejemplo, en el inicio de un proceso judicial de esta naturaleza solo por la denegatoria de una licencia de funcionamiento o una licencia de construcción a nivel municipal, solicitada exclusivamente para fines domésticos.

El beneficio de obtener una solución al problema en vía administrativa, por lo demás, resulta ambivalente en la medida que beneficia tanto al administrado como a la Administración quien no tiene que verse sometida a un proceso judicial con el correspondiente compromiso de recursos públicos que eso significa. Así, establecer una regla según la cual todos los cuestionamientos a la Administración Pública deban dar lugar inmediatamente al inicio de un proceso contencioso administrativo supondría inundar a las entidades de procesos judiciales, los mismos que, evidentemente, serían costeados con recursos públicos.

Por otro lado, la propuesta de hacer potestativos los recursos administrativos o de suprimirlos deja de lado la observación de que el sistema de recursos administrativos se configura también como una forma de control institucional ${ }^{4}$, en la medida que a través de éstos, muchas veces, la Administración puede ejercer un control interno producto de sus reglas de jerarquía o tutela en las organizaciones públicas. Así, los recursos se configuran como una herramienta de información que facilita el autocontrol de la Administración Pública y que pone en evidencia, ante la mirada de los superiores jerárquicos, la actuación de determinados órganos administrativos.

3 Esteve Pardo, José, Lecciones de Derecho Administrativo, Marcial Pons, Madrid, 2014, p. 227.

4 De Asís Roig, Agustín, Los recursos administrativos de reposición y de alzada. En: Revista Documentación Administrativa No. 254-255, Mayo-Diciembre, INAP, Madrid, 1999, p. 269. 
Tal vez por ello coincidamos con aquellos que consideran que la mejor alternativa resulta reconocer las debilidades que ofrece el sistema de recursos administrativos por su propia naturaleza y, a partir de ello, establecer la regulación más adecuada que permita que este sistema funcione de la mejor manera posible 5 . Y es que no cabe duda de que se trata de un sistema que debe mantenerse en constante revisión para evitar que los recursos dejen de cumplir con todas aquellas funciones que tienen encomendadas por su naturaleza.

De acuerdo con lo propuesto hasta el momento, en consecuencia, es posible afirmar que, según la doctrina, los recursos administrativos cumplen con distintas funciones:

(i) Garantía para los administrados.- Muchos autores consideran que los recursos constituyen un mecanismo de garantía de los administrados en la medida que a través de aquellos éstos pueden solicitarle a la Administración que revise su decisión de una manera menos formal y más expeditiva de lo que supondría iniciar un proceso contencioso administrativo.

(ii) Control de legalidad.- Es posible afirmar también que los recursos forman parte de un sistema institucional de control de legalidad de la actuación administrativa. Ello en la medida que, a través de su ejercicio, es posible verificar si la Administración está sujetándose a los controles de legalidad propios de su actuación en un Estado constitucional. De esta manera, se permite que la Administración evalúe desde su interior la regularidad en la actuación de los órganos que la componen.

(iii) Autocorrección de la Administración Pública.- Como se ha señalado, otra de las concepciones características de los recursos administrativos es aquélla que viene dada por estimar que los recursos se configuran como una manifestación de la autotutela de la Administración Pública y, en ese sentido, se constituyen como un privilegio de la Administración que provoca el sometimiento al administrado a la obligación de pedirle que revise alguna de sus decisiones en lugar de sujetarse directamente a la jurisdicción ordinaria como todos los ciudadanos. La función de los recursos desde esta perspectiva sería, entonces, la de permitir a la Administración que corrija su decisión sin la necesidad de verse involucrada en un proceso judicial para ello.

(iv) Vía para administrativizar asuntos inter privatos.- Finalmente, como exponen algunos profesores ${ }^{6}$, hoy en día, los recursos administrativos se han constituido en una forma de administrativizar algunos conflictos que en principio operan entre sujetos privados. Tal es el caso de las industrias dedicadas a la

5 Rodríguez-Arana, Jaime y SENDÍN, Miguel Ángel, Derecho Administrativo Español, Editorial Netbiblo, Tomo II, La Coruña, 2009p. 271.

6 Escuin Palop, Vicente y Belando Garín, Beatriz, Los recursos administrativos, Civitas Thomson Reuters, Navarra, 2011, p. 50. 
prestación de servicios públicos en nuestro país, en cuyo caso el ordenamiento usualmente exige que las reclamaciones de los usuarios se hagan valer, en primer término, ante las empresas prestadoras del servicio y solo en caso no se obtenga una decisión satisfactoria, será posible recurrir al organismo regulador correspondiente. Es, entonces, a través de la vía del recurso administrativo que se acude a una autoridad administrativa para poner en su conocimiento un asunto que originalmente podía ser considerado inter privatos.

Ahora bien, como es evidente, cada ordenamiento jurídico, en atención a sus circunstancias particulares, propone una serie de regulaciones de las cuales deben ser objeto lo recursos administrativos, con mayores o menores exigencias, o con definiciones especiales para su trámite. Muchas veces un análisis de estas regulaciones permite evidenciar cual de todas las funciones antes referidas es la que ha decidido priorizar el legislador en determinado ordenamiento. De la regulación establecida para el trámite de los recursos administrativos en el caso peruano nos ocuparemos en las líneas que siguen a continuación.

\section{Actuaciones objeto de impugnación}

Indudablemente, uno de los aspectos más relevantes dentro del estudio del régimen legal de los recursos administrativos lo constituye la definición de qué actos emitidos por la Administración Pública pueden ser considerados objeto de impugnación. Por supuesto, cada ordenamiento resuelve esta pregunta de manera distinta, sin embargo, existe cierto consenso en considerar que en la medida que un procedimiento administrativo constituye muchas veces una larga de secuencia de actos de la Administración, no todas las decisiones que la entidad adopte en su desarrollo pueden ser objeto de impugnación toda vez que esto tornaría el procedimiento en interminable $y$, en consecuencia, en inútil.

En este contexto, el ordenamiento peruano ha regulado a través de dos disposiciones contenidas en la Ley del Procedimiento Administrativo General los casos en los cuales procede la contradicción de decisiones administrativas a través de la interposición de recursos administrativos. Así, por un lado, en el artículo $109^{\circ}$ de la LPAG, situado orgánicamente en el capítulo correspondiente al inicio del procedimiento administrativo, el legislador ha establecido que cabe cuestionar cualquier acto que viole, afecte, desconozca o lesione algún derecho o interés legítimo en la forma prevista por esta ley. De una revisión de las disposiciones posteriores es posible afirmar que la "forma prevista por esta ley" es aquella que viene concretizada en el artículo $206^{\circ}$ de la referida norma, el mismo que, además de reiterar esta regla general de contradicción, delimita el objeto de impugnación señalando que únicamente pueden ser cuestionados a través de recursos administrativos: (i) los actos definitivos que ponen fin a la instancia, (ii) los actos de trámite que determinen la imposibilidad de continuar con el procedimiento administrativo, o (iii) los actos de trámite que sitúen al administrado en un supuesto de indefensión. 
En el primero de los casos, no cabe duda de que el legislador se refiere a aquél acto administrativo que es probablemente la razón de ser del procedimiento administrativo, es decir, al acto que es el objetivo que se busca lograr una vez iniciado el procedimiento administrativo. En ese sentido, se está haciendo referencia a aquél acto que aprueba o deniega una licencia, al que impone una sanción, al que deniega una pensión, al que aprueba el otorgamiento de la buena pro en el marco de un proceso de selección, etc. Como es evidente, ante un acto de esta naturaleza, en tanto se configura como una decisión definitiva que genera efectos directos para un administrado determinado, corresponde que proceda su impugnación a través de los recursos administrativos correspondientes.

Asimismo, el legislador ha establecido que también procede, excepcionalmente, la impugnación de actos de trámite. El rasgo de excepcionalidad se deduce porque para que proceda la impugnación de un acto de esta naturaleza, el legislador exige que éstos cumplan con ciertas condiciones como es el caso en el cual el acto de trámite impide continuar con el procedimiento administrativo o genera un supuesto de indefensión en el administrado. El primero de los casos puede venir dado por aquel acto que declara el abandono en el procedimiento administrativo por asumirse la falta de interés del administrado. El segundo puede configurarse, entre otros casos, cuando un acto de la Administración deniega al administrado aportar medios probatorios por considerar que éstos no son pertinentes.

Es evidente que esta excepcionalidad radica en la consideración de que solo aquellos actos de trámite que puedan tener consecuencias graves y directas para los administrados puedan ser objeto de impugnación y no aquellos que simplemente tienen efectos indirectos o que suponen un mero impulso para la continuación de un procedimiento.

De estas disposiciones también se extraen otras conclusiones importantes como aquella que permite afirmar que en el marco de un procedimiento administrativo no todo acto administrativo, por solo tener la calidad de tal, resulta impugnable. Piénsese, por ejemplo, en el caso del acto administrativo de imputación de cargos a través del cual se da inicio a un procedimiento administrativo sancionador. Es claro que, a menos que por serios defectos formales se constituya en un acto que cause indefensión, nos encontramos ante un acto administrativo pero no frente a un acto impugnable.

Ahora bien, el hecho de que no nos situemos frente a un acto impugnable pero éste incurra en algún vicio o cause algún agravio al administrado, no quiere decir en ningún caso que aquellos actos no puedan ser objeto de cuestionamiento por otra vía. La misma norma establece residualmente que para el caso de los demás actos que deban ser objeto de cuestionamiento lo que debe hacer el administrado es alegar su cuestionamiento en el momento pero esperar el acto definitivo para cuestionarlos por la vía del recurso administrativo correspondiente. En este supuesto, de verificarse la nulidad del acto de trámite se deberá valorar si ésta también genera la nulidad del acto 
final o si es un hecho perfectamente subsanable en cuyo caso se deberá preferir la conservación del acto.

A este respecto, por lo demás, hay que decir que, por reglas elementales de debido procedimiento, la falta de denuncia oportuna de los actos irregulares no impide la posibilidad de impugnación posterior vía recurso. Esto porque, además, debe entenderse que las irregularidades en la actuación de la Administración, sujeta siempre a la legalidad, no pueden quedar convalidadas en este caso, solo porque no fueron alegadas en su momento por parte del administrado ${ }^{7}$.

En relación con aquellos actos que no son impugnables por la vía de los recursos administrativos, es importante tomar en cuenta que existe también la alternativa de la queja por defectos de tramitación. Una herramienta de naturaleza no impugnativa a disposición del administrado que tiene por finalidad denunciar la comisión de irregularidades en el desarrollo de un procedimiento administrativo frente al superior jerárquico del órgano encargado de tramitar el mismo, con la finalidad de remitirle una denuncia por incumplimiento de las normas procedimentales correspondientes. De este modo, el administrado tiene a su disposición otro mecanismo de corrección o remedio procesal $^{8}$ que, pese a no tener naturaleza impugnativa, puede ayudarlo a solicitar la revisión de alguna presunta irregularidad formal.

Ahora bien, no obstante la importancia de estas alternativas, consideramos que la delimitación del concepto de acto impugnable resulta trascendental en la medida que la vía del recurso administrativo es una camino inmediato y efectivo para que el administrado reaccione frente a un hecho que le puede causar agravio. Si bien entendemos que el objetivo del legislador ha sido delimitar lo más posible el uso de los recursos administrativos para que éstos sean utilizados solo en aquellas situaciones en las que resultan verdaderamente necesarios, lo cierto es que consideramos que, muchas veces, la definición resulta ser demasiado estricta y termina dejando fuera de su ámbito actos cuyo cuestionamiento debería permitir la interposición de un recurso administrativo.

Así, por ejemplo, en ninguno de los supuestos de acto impugnable es posible enmarcar la posibilidad de interponer un recurso administrativo contra el dictado de una medida provisional o medida cautelar dictada en el marco de un procedimiento administrativo. Como sabemos, las medidas de esta naturaleza, pese al indudable agravio que pueden causar al administrado, no constituyen un acto administrativo definitivo y no necesariamente pueden considerarse actos de trámite que causen indefensión en todos los casos. Recuérdese que, a diferencia de lo dispuesto en sede judicial, en la regulación del procedimiento administrativo no está claro que una medida cautelar

7 Esteve Pardo, José, Lecciones de Derecho Administrativo, Marcial Pons, Madrid, 2014, p. 228.

8 Morón Urbina, Juan Carlos, Los recursos en la Ley del procedimiento administrativo general y en los procedimientos sectoriales, Gaceta Jurídica, Lima, 2009, p. 55. 
deba dictarse siempre inaudita parte, razón por la cual pueden existir medidas provisionales que hayan sido dictadas sin desatender el derecho de defensa de un administrado ${ }^{9}$. En ese caso, es decir en aquél supuesto en el que una medida cautelar no genera per se un situación de indefensión, ¿cómo podría ser impugnada en caso el administrado estime que la medida preventiva es ilegal y que le causa un agravio irreparable? ¿Tendría el administrado que esperar a que se dicte el acto definitivo para poder cuestionar recién en ese momento la decisión?

Evidentemente una respuesta negativa a esta última pregunta supondría el riesgo de generarle un grave perjuicio a un administrado, quién sabe irreparable, solo por no permitírsele hacer uso de un recurso administrativo, en este caso, porque la ley no lo prevé así.

Un supuesto parecido se presenta frente a aquellos actos dictados por la Administración cuyo incumplimiento puede generar un perjuicio irreparable. Piénsese en un supuesto en el cual la Administración solicita al administrado, como parte de la instrucción del procedimiento administrativo, información que se encuentra protegida por la propiedad intelectual de un tercero no implicado en el procedimiento. En un caso como éste, si el administrado cumple con el mandato de la Administración estaría vulnerando un derecho fundamental, sin embargo, no posee una herramienta con la entidad suficiente para defenderse ante este mandato, como es el caso de un recurso administrativo. Para estos actos, como es posible apreciar, no basta contar con una regla según la cual se deba esperar hasta la emisión del acto definitivo para impugnar la decisión porque el perjuicio que se genere puede resultar irreparable.

Finalmente, cabe advertir que una redacción poco feliz de la norma podría llevarnos a la conclusión de que, en el caso de los actos administrativos, únicamente aquel acto que pone fin a la instancia es aquel que resulta un acto impugnable. Esto en la medida que cuando la norma se pronuncia sobre las actuaciones que causen indefensión o impidan continuar con el procedimiento como actuaciones impugnables, hace referencia únicamente a los "actos de trámite". Al respecto, debe quedar claro que también los actos administrativos que, aun no siendo actos que ponen fin a la instancia, afecten del derecho de defensa del administrado o impidan continuar con el procedimiento serán actos impugnables por la vía recursiva. Y es que es evidente que si un acto de trámite puede afectar el derecho de defensa o impedir continuar con el

9 En relación con la audiencia previa al dictado de una medida provisional la doctrina ha señalado que: "La conclusión a la que podemos llegar es que siempre que sea posible y dado el contenido gravoso y limitativo de estas medidas, deberá darse audiencia al interesado o destinatario de la medida. En otras ocasiones, si el trámite no está previsto en la norma reguladora del procedimiento, si la urgencia exige la adopción de la medida con carácter inmediato y si además, la audiencia no aporta dato relevante alguno a la evidente gravedad de los hechos podrá adoptarse la medida directamente." Meseguer Yebra, Joaquín. Las medidas provisionales en vía administrativa, Bosch, Madrid, 2000, p. 19. 
procedimiento, un acto administrativo dictado en medio de un procedimiento administrativo también puede hacerlo.

No tenemos duda de que una interpretación conforme con el principio del debido procedimiento debería llevar al funcionario público a la conclusión de que en todos estos casos si debería proceder la impugnación de estas decisiones vía recurso administrativo, sin embargo, haría muy bien el legislador en establecer claramente una redacción menos estricta a fin de que la regla de legalidad a la que se encuentran sujetos los funcionarios no limite la posibilidad de que se ejerza el derecho de defensa en estos casos.

\section{Legitimidad para recurrir}

Si se parte de la premisa de que en todos los posibles procedimientos administrativos que desarrolle alguna entidad pública es posible reconducirnos hacia un interés público ulterior, cualquiera que sea su naturaleza, teóricamente, cualquier administrado podría tener interés en que las decisiones que adopte la Administración sean legales y compatibles con el interés público protegido en cada situación. Sin embargo, por evidentes razones de seguridad jurídica, el legislador ha determinado que solo pueden impugnar una decisión, por la vía de un recurso administrativo, aquellos administrados que cuentan con un interés legítimo, personal, actual y probado. Así lo señala el artículo $109^{\circ}$ de la LPAG.

Es posible afirmar, entonces, que salvo los supuestos de acciones públicas o intereses difusos, existe una legitimación restringida de acuerdo a ley en relación con la facultad para interponer recursos administrativos. De este modo, según lo estimado por el legislador, solo aquel administrado que resulte directamente afectado en su esfera de derechos o intereses podrá considerarse con la aptitud legal para actuar o contradecir la actuación de la Administración Pública a través de la vía de un recurso administrativo.

El administrado recurrente es, en consecuencia, aquél que puede situarse en cualquiera de los siguientes dos supuestos. En primer lugar, se trata de un administrado que ostenta un derecho que puede verse favorecido o perjudicado a partir de lo dispuesto por la autoridad en el marco de determinado procedimiento administrativo. Es decir, se trata de un administrado cuyos derechos pueden verse afectados directamente. Al respecto, conviene tener en cuenta que nos referimos a derechos previamente reconocidos por el ordenamiento jurídico. Tal sería el caso del administrado que se ve perjudicado en su derecho de propiedad al disponerse el decomiso de sus bienes o su derecho a la libertad de empresa porque una resolución administrativa le ha denegado una licencia de funcionamiento sin la cual no puede operar en el mercado.

El segundo supuesto es aquél que se produce cuando el administrado no cuenta con un derecho legalmente reconocido pero sí con un interés legítimo al respecto. Como ha señalado la doctrina este interés legítimo puede entenderse como "la situación en la 
que se encuentra una persona en relación con una actuación administrativa ante la que carece de un derecho subjetivo de naturaleza sustantiva frente a la Administración, pero de la que puede derivarle un beneficio o un perjuicio" ${ }^{\prime 10}$. De este modo, el interés legítimo es aquello que singulariza a un ciudadano respecto de la situación general en la que se sitúan los demás administrados en relación con el objeto de determinado procedimiento administrativo. Este podría ser el caso del propietario de una casa de playa frente al mar que quiere contradecir el acto que aprueba la licencia de construcción de una empresa que pretende construir más pisos de los permitidos legalmente obstaculizando el paisaje que el vecino afectado tiene al frente.

En sede nacional, la doctrina ${ }^{11}$ ha explicado con suficiente claridad qué supuestos deben concurrir para considerar que nos encontramos ante un tercero legitimado para recurrir, de acuerdo a lo previsto expresamente por el artículo $109^{\circ}$ de la ley. En ese sentido, se ha señalado que el interés alegado por el administrado para ser legítimo, y en consecuencia para que resulte procedente un recurso administrativo, debe contar con las siguientes características: (i) Ser personal, esto es, que el objeto del acto cuestionado afecte directamente al recurrente y no se aleguen solo los intereses generales de la colectividad, salvo los supuestos permitidos por ley de intereses difusos; (ii) Ser actual, esto es, el acto cuestionado debe tener incidencia efectiva en el administrado al momento en el que éste pretende cuestionarlo, de manera que no puede tratarse de una posible afectación, remota, hipotética o potencial; y finalmente (iii) Ser probado, es decir, que no basta la mera alegación de afectación sino que recae sobre el administrado recurrente la exigencia de probar que él tiene un interés legítimo involucrado en el procedimiento administrativo.

Por último, merece la pena referirnos a un supuesto singular como es el caso del derecho de impugnación del administrado denunciante. Tal como lo prevé el artículo $143^{\circ}$ de la Ley No. 27444 , el denunciante cuenta con derechos muy limitados al no encontrarse reconocido como sujeto o parte del procedimiento administrativo. De este modo, entre otras cosas, el denunciante no puede interponer un recurso administrativo contra ninguna decisión que se adopte en el marco del procedimiento administrativo que pudiera haberse originado por el mérito de su propia denuncia. Por supuesto, existen suficientes fundamentos para ello como la regla fundamental de que los procedimientos administrativos sancionadores únicamente se inician de oficio.

No obstante, conviene tener en cuenta que la regla general según la cual los denunciantes no pueden interponer recursos administrativos, debe entenderse únicamente aplicable al caso de los administrados denunciantes que no cuentan con un interés legítimo involucrado en el acto que denuncian. Y es que también en el caso del denunciante es posible distinguir a aquel que da cuenta a la Administración de alguna

10 Escuin Palop, Vicente y Belando Garín, Beatriz. Los recursos administrativos, Civitas Thomson Reuters, Navarra, 2011, p. 112.

11 Seguimos en esta descripción las definiciones propuestas por Morón Urbina, Juan Carlos. Comentarios a la Ley del Procedimiento Administrativo General, Gaceta jurídica, Novena edición, Lima, 2011, p. 416-417. 
presunta irregularidad que, pese a no afectarle directamente, pone en riesgo la tutela de algún interés público, de aquel otro que presenta una denuncia motivado porque el acto del que da cuenta a la entidad lo agravia directamente. A manera de ejemplo, es éste el supuesto contemplado en la mayoría de los casos de protección al consumidor, supuestos en los cuales, usualmente el denunciante es también el afectado y, en consecuencia, cuenta con un interés que lo legitima para poder interponer un recurso administrativo.

\section{Regulación de la admisibilidad y procedencia}

Tal como ha quedado señalado previamente, la finalidad de un administrado al interponer un recurso administrativo no es otra que la de obtener la nulidad o la modificación de una actuación administrativa en cierto sentido. Si se toma esta premisa en consideración, la conclusión obvia es que el recurso administrativo debe encontrarse fundamentado en alguna de las causales de nulidad contempladas en el artículo $10^{\circ}$ de la LPAG, en la medida que aquellas son las únicas razones que podrían llevar a la entidad pública a declarar la nulidad de su decisión administrativa tanto para dejarla sin efectos como para modificarla.

Si bien es cierto que muchos autores han considerado que a través de los recursos administrativos también se puede solicitar la gracia de la Administración para modificar su decisión no solo debido a la existencia de una causal de nulidad, creemos que, actualmente, una actuación en este sentido solo estaría permitida en supuestos realmente excepcionales en la medida que su utilización frecuente o regular podría atentar contra el tratamiento igualitario hacia los administrados concretamente manifestado en los principios de uniformidad y predictibilidad del procedimiento administrativo reconocidos por la propia ley. $Y$ es que no está de más recordar que este tipo de gracias constituyen vestigios del Estado pre constitucional en el que este tipo de privilegios otorgados por las autoridades ponía en cuestión los alcances de la igualdad.

En todo caso, consideramos que aquellos supuestos que no se encuentran sustentados en alguna causal de nulidad como tal deberían ser los menos. Tal vez sería el caso de aquel recurso que no se sustenta en algún vicio de nulidad sino en una incorrecta apreciación de criterios de graduación de sanciones que, quizás, no determinarían la nulidad del acto pero sí su eventual modificación si el administrado cuenta con las razones suficientes para que su recurso sea fundado ${ }^{12}$.

Ahora bien, debe quedar claro también que la fundamentación que lleve a cabo el administrado respecto de las razones que sustentan su impugnación puede responder a fundamentos de hecho y de derecho. A diferencia de lo que ocurre en algunos casos en sede judicial, en el caso del procedimiento administrativo, la doctrina siempre ha entendido que cualquier recurso administrativo puede estar sustentado tanto en

12

Esteve Pardo, José, Lecciones de Derecho Administrativo, Marcial Pons, Madrid, 2014, p. 225. 
razones fácticas como jurídicas. De este modo, el administrado puede válidamente obtener la anulación o la modificación de un acto administrativo tanto porque a través del recurso con una prueba nueva pudo probar que él no fue quien cometió la infracción que se le imputa o porque, a través de la vía de la interpretación jurídica, logra probar que el hecho descrito como infracción en determinada ley no constituye la misma conducta que él ha llevado a cabo.

Por supuesto, el recurso administrativo interpuesto por el administrado también puede cuestionar una decisión administrativa por razones de fondo o de forma. Así, la Administración deberá declarar fundado un recurso administrativo, por ejemplo, cuando la vulneración del derecho al debido procedimiento alegada por el administrado sea comprobada o cuando se confirme que efectivamente un administrado debió ser calificado con un mejor puntaje en el marco de determinado proceso de selección porque cumplía con una serie de condiciones exigidas en las bases del concurso.

Demás está decir que el mismo fundamento permite que el administrado solicite a través de un recurso administrativo tanto la nulidad total como la nulidad parcial de una decisión administrativa. Una premisa como ésta puede encontrar un doble fundamento. De un lado, el fundamento más general nos remite a la idea de estabilidad y conservación del acto administrativo según la cual si solo una pieza perfectamente separable del acto administrativo adolece de una causal de nulidad no existiría ninguna razón para declarar la nulidad del acto administrativo en su integridad. Sin embargo, por otro lado, es posible comprender que esta premisa también encuentra un fundamento garantista para el administrado que se basa en no exigirle al mismo el cuestionamiento del acto administrativo en su integridad como requisito para que proceda su impugnación por la vía recursiva sino que basta con que una pieza del acto administrativo, perfectamente divisible, sea nula para que la solicitud de anulación sea legítima.

Y es que, como puede apreciarse de la elaboración de estas últimas precisiones, lo que se busca en el marco de la idea del sometimiento de la Administración a la legalidad plena, es fomentar una amplitud de control ${ }^{13}$, también por parte del administrado, sobre cada una de las decisiones que aquélla adopta. De este modo, si desde la regulación restringida del acto impugnable y de la legitimidad para recurrir se establecen más bien reglas estrictas para que no cualquier acto pueda ser cuestionado por cualquier sujeto, en este caso se establecen reglas amplias que permitan generar un balance a favor también de la amplitud de control de la actuación administrativa. No puede dejar de tomarse en cuenta, por lo demás, que en la medida que la interposición de recursos está vinculada directamente a un derecho fundamental, como es el caso del derecho de defensa o el debido procedimiento, el criterio interpretativo

13 Parejo Alfonso, Luciano, Lecciones de Derecho Administrativo, Tirant Lo Blanch, Valencia, 2013, p. 636. 
que debe primar en cuanto al análisis de su procedencia será siempre el de favor actionit $^{14}$.

Más allá de estas consideraciones, la regulación general de los requisitos del recurso administrativo establecida en el artículo $211^{\circ}$ de la Ley No. 27444 señala que a éstos le aplican los mismos requisitos que aquellos exigibles a los escritos que, en general, son presentados a cualquier entidad de la Administración Pública y cuyos alcances se encuentran regulados en el artículo $113^{\circ}$ de la LPAG.

La única exigencia adicional, de acuerdo con el referido artículo $211^{\circ}$ de la Ley, parecería ser aquella que establece como requisito de admisibilidad del recurso la firma de un abogado. Un requisito que, por lo demás, resulta a todas luces cuestionable. En primer lugar, porque si, como hemos señalado, un recurso administrativo puede encontrarse sustentado en razones tanto de hecho como de derecho, ¿por qué sería necesario contar con el auxilio legal para que el administrado explique por escrito los hechos que justifican su petición? Si bien, en nuestra opinión, la exigencia de autorización letrada no debería proceder en ninguno de los dos supuestos, queda claro que en el supuesto en el que un recurso administrativo se justifique únicamente en razones de hecho, esta exigencia se transforma en un obstáculo injustificable para el administrado.

Es todavía más difícil entender por qué el legislador establece un requisito como tal si, precisamente, tal como señaláramos, una de las ventajas y razones que justifican la subsistencia de los recursos administrativos radica en la facilidad de su trámite y en los menores costos que el procedimiento recursivo importa frente a la activación de un proceso judicial. En ese sentido, el establecimiento de una exigencia como ésta desnaturaliza la propia idea del procedimiento de impugnación y termina erigiéndose como una limitación ilegítima al derecho de defensa del administrado.

Por otro lado, una exigencia que vale la pena resaltar es la del sometimiento de los recursos a un plazo perentorio para su interposición. Como se sabe, el artículo $207^{\circ}$ de la Ley establece que los recursos administrativos deberán ser interpuestos en un plazo máximo de quince (15) días después de que haya quedado consentido el acto objeto de impugnación. Sobre el particular, es evidente que el legislador ha considerado relevante establecer un plazo perentorio con un criterio de seguridad jurídica de manera que las decisiones de la Administración no queden sometidas de manera indefinida a la libertad de los particulares para cuestionarlas y promover que sean dejadas sin efecto. Se entiende que abrir una puerta en ese sentido eliminaría cualquier atisbo de predictibilidad y estabilidad jurídica de la que, más bien, deben gozar las decisiones administrativas.

Se trata, sí, de un plazo indudablemente breve pero también razonablemente suficiente para que un administrado pueda plantear una argumentación que permita 
cuestionar las razones por las cuales la Administración ha adoptado determinada decisión. No obstante, conviene destacar que, debido a la naturaleza perentoria de este plazo, las consecuencias de la no interposición de un recurso administrativo a tiempo pueden ser gravísimas en la medida que el acto puede devenir incuestionable y, en consecuencia, no procedería ningún tipo de acción en su contra por estimarse consentido.

Ahora bien si se entiende también que nos encontramos ante un plazo de caducidad como afirma la doctrina, debe señalarse que la interposición de un recurso que no resultara procedente no debería suspender el cómputo del plazo total de quince (15) días $^{15}$. Es decir, que si, por ejemplo, diez (10) días después de consentido el acto administrativo objeto de impugnación se interpone un recurso que resulta siendo improcedente pues debe entenderse que no quedan más que los cinco (5) días restantes para que el administrado pueda presentar un nuevo recurso buscando su procedencia. En la mayoría de los casos, como es evidente, la Administración resolverá sobre la procedencia del recurso después de ese plazo de cinco (5) días o, mejor dicho, después del cumplimiento del plazo total para la interposición del recurso, razón por la cual será imposible presentar un nuevo recurso porque el plazo para la presentación del mismo habrá caducado.

Los fundamentos de estas premisas son consecuencia de la valoración del principio de seguridad jurídica toda vez que se busca establecer un plazo específico de manera que una decisión de la Administración no se encuentre permanentemente expuesta a cuestionamientos que puedan determinar su invalidación. Sin embargo, conviene preguntarse si esta consecuencia derivada de la fijación de este plazo perentorio debería aplicarse en el mismo sentido en todos los casos tal y como lo ha previsto el legislador en la Ley No. 27444.

En concreto, llama la atención que en los casos de solicitudes de reconocimiento de derechos el solo hecho de que no se haya impugnado a tiempo una decisión desestimatoria genere como consecuencia la eliminación de toda posibilidad para solicitar un derecho en la vía administrativa. Pensemos, por ejemplo, en el supuesto de un administrado que solicita una pensión a la Administración porque ésta legalmente le corresponde. El órgano que atiende su solicitud se equivoca en la apreciación de los requisitos y determina, erróneamente, que el administrado no cuenta con derecho a la pensión solicitada. Este administrado que vive solo y tiene más de sesenta años, olvida presentar el recurso a tiempo y lo interpone recién en el día veinte. ¿El solo transcurso de un plazo tan breve debería eliminar toda posibilidad de que el administrado pueda defenderse en un caso del reconocimiento de un derecho que le corresponde? ¿Qué sucedería si no hubiera un plazo perentorio en estos casos? ¿Se afectaría la seguridad jurídica o los derechos de terceros?

15 Rodríguez-Arana, Jaime y Sendín, Miguel Ángel, Derecho Administrativo Español, Editorial Netbiblo, Tomo II, La Coruña, 2009, p. 272. 
Por supuesto, entendemos que exista un plazo perentorio en la mayoría de los casos y que éste sea la regla general en materia de recursos administrativos. En el caso de un procedimiento sancionador es obvio que debe existir un plazo perentorio para la impugnación porque se requiere terminar el procedimiento para castigar una inconducta o para poder hacer cumplir la sanción o ejecutarla forzosamente. Lo mismo en el caso de la impugnación de una buena pro toda vez que de dilatarse el trámite de impugnación se podría perjudicar a los terceros participantes de un proceso de selección o a la propia entidad que requiere de un bien o servicio con cierta prontitud. Pero en los casos en los que el administrado se sitúa en un procedimiento frente a la administración solicitando el reconocimiento de un derecho que le asiste, crealmente existen razones para establecer un plazo perentorio? ¿Se perjudica a alguien si el recurso administrativo no estuviera sujeto a ningún plazo y el administrado pudiera interponerlo en cualquier momento?

Creemos que no. Estimamos que la eliminación del plazo perentorio para impugnar en el caso de reconocimientos de derechos debería ser una alternativa a considerar por parte del legislador. Ello en la medida que la falta de diligencia o el solo transcurso del tiempo en casos como éstos no pueden habilitar a la Administración a desconocer derechos legítimamente reconocidos en el marco del ordenamiento jurídico.

Si bien no existe más regulación que aquella presentada en cuanto a los requerimientos para dar trámite a un recurso administrativo, en lo que sí existe más detalle ofrecido por la regulación y la doctrina es en cuanto a aquello que no se puede exigir al administrado para definir si su impugnación debe ser tramitada o no por la entidad pública. Al respecto, conviene resaltar tres reglas particularmente relevantes.

De acuerdo con el artículo $213^{\circ}$ de la LPAG, el error en la calificación de un recurso administrativo no puede ser un obstáculo para su tramitación. Se entiende, así, que si el administrado se equivoca en la denominación del recurso administrativo en el escrito que lo contempla, este hecho no podrá constituir una justificación válida para que la Administración deje de aceptar el recurso. Por el contrario, ante un hecho de esta naturaleza, la entidad tendrá el deber de corregir el error y darle el trámite que corresponda considerando las características del recurso que le permitan evidenciar cuál fue la verdadera intención del administrado. Se trata, indudablemente, una expresión del viejo principio procesal del iura novit curia, aplicable ordinariamente a la sede judicial.

Por otro lado, tampoco es posible exigir el cumplimiento del acto objeto de impugnación para que el recurso administrativo proceda ${ }^{16}$. Se considera proscrita la regla solve et repete por estimarse vulneratoria del debido procedimiento. $Y$ es que, evidentemente, si la validez de un acto se encuentra siendo objeto de cuestionamiento no puede exigírsele al administrado su cumplimiento como requisito para que proceda la interposición de un recurso administrativo. Esta regla resulta particularmente general y en los procedimientos sectoriales, Gaceta Jurídica, Lima, 2009, p. 10. 
relevante para los recursos que cuestionan actos que imponen a los administrados obligaciones de dar o hacer con las que éstos no se encuentran conformes.

Finalmente, no se configura como un requisito para la procedencia del recurso administrativo el aporte de material probatorio adicional al que se haya incluido en el desarrollo del procedimiento que dio lugar al acto objeto de cuestionamiento ${ }^{17}$. Si bien es cierto que en el caso del recurso de reconsideración se exige la presentación de una nueva prueba como requisito de procedencia del recurso debe entenderse que en ese caso nos encontramos ante un supuesto excepcional que responde a la naturaleza singular de este recurso, como explicaremos más adelante. $Y$ es que, como es evidente, el administrado puede plantear un recurso administrativo que se sustente en una interpretación distinta de los hechos más que en hechos nuevos o en el cuestionamiento a la interpretación legal formulada por la Administración. Si esto es así, obligar al administrado a presentar pruebas como requisito de procedencia de su recurso terminaría constituyendo un despropósito.

Ahora bien, como es evidente, no existe ningún obstáculo para que el administrado pueda presentar medios probatorios acompañando el recurso administrativo. Por el contrario, el aporte de material probatorio forma parte de su derecho de defensa y del respeto al debido procedimiento, razón por la cual él cuenta con plenas facultades para ello. Y, por lo demás, cabe destacar que puede hacerlo no solo en el momento de la presentación del recurso sino en cualquier momento durante el trámite del mismo sin importar que se trate de hechos nuevos.

\section{Clases de recursos}

El ordenamiento jurídico administrativo peruano contempla tres tipos de recursos administrativos que el administrado puede utilizar para reaccionar frente a una decisión de la Administración que considera cuestionable. Así como existen reglas comunes para ellos, algunas de ellas ya expuestas, también es cierto que existen características muy específicas que se aplican a cada uno en particular. A continuación nos referiremos a la regulación establecida para los recursos de reconsideración, apelación y revisión previstos en la LPAG.

\subsection{Recurso de reconsideración}

El primero de ellos, el recurso de reconsideración, tiene naturaleza opcional debido precisamente a los términos bajo los cuales éste se tramita. Y es que este recurso es uno que se puede interponer frente al mismo órgano que emitió la decisión objeto de cuestionamiento con la finalidad de que éste vuelva a revisar la decisión adoptada. Evidentemente, las probabilidades de éxito serían muy pocas si es que en el escrito del recurso solo se plantea una nueva explicación sobre por qué la decisión de la entidad pública debe ser adoptada en otro sentido. Tal vez por ello, la norma establece como requisito para la procedencia de este recurso la exigencia de contar con una prueba

Op. Cit. p. 12. 
nueva. Es decir, para que un recurso de reconsideración pueda ser tramitado por la Administración éste debe ir acompañado de una prueba distinta a todas aquellas que fueron incorporadas al procedimiento que derivó en el acto objeto de impugnación. Se entiende, entonces, que solo ante la revelación de un hecho nuevo el mismo órgano que tomó la decisión podría cambiar el sentido de la misma.

Ahora bien, de un análisis de los artículos encargados de regular el recurso de reconsideración es posible apreciar que el legislador no ha regulado las características que debe tener la nueva prueba que debe acompañar a este tipo de recurso. En ese sentido, con la finalidad de llevar a cabo una interpretación conforme con el debido procedimiento de los administrados, la nueva prueba debe entenderse en un sentido amplio, de manera que cualquier hecho nuevo del que no se haya dado cuenta a la autoridad administrativa o cualquier información contenida en cualquier instrumento que no haya sido objeto de evaluación en el marco del procedimiento que dio origen a la decisión objeto de cuestionamiento puede ser considerado una nueva prueba. Además de este requisito natural, consideramos que la única exigencia adicional que puede ofrecerse es que el referido medio probatorio guarde un mínimo de pertinencia con los hechos o fundamentos que se discuten en el procedimiento.

Por lo demás, no puede dejar de tomarse en cuenta que en caso, por error, el administrado olvide adjuntar una nueva prueba o equivoque su presentación, lo que corresponde es otorgar un plazo para que éste pueda subsanar el error ${ }^{18}$, con la finalidad de no dejarlo desprovisto de la vía de defensa que supone la reconsideración.

Debe señalarse también que se trata del único recurso que podrá ser interpuesto en los casos en los que el órgano que emitió la decisión no se encuentre sometido a jerarquía y que, en esos supuestos, con la finalidad de garantizar el derecho de defensa del administrado, se podrá prescindir de la exigencia de contar con una nueva prueba como requisito de procedencia del recurso. En estos casos, además, su carácter opcional se manifiesta concretamente en el hecho de que no es necesaria su interposición como requisito previo para acudir a la vía judicial ${ }^{19}$. Dicho de otra manera, la decisión de un órgano no sometido a jerarquía agota la vía administrativa sin que se necesite interponer una reconsideración contra esta decisión, salvo disposición legal especial que establezca lo contrario.

Ahora bien, tal como señalamos, se trata de un recurso opcional de manera que el administrado puede prescindir de su interposición, más aún si no cuenta con una prueba nueva, y puede decidir acudir directamente al recurso de apelación o jerárquico en el que el trámite de la impugnación será seguido por el órgano superior jerárquico a aquel que emitió la decisión cuestionada. Hay que decir, entonces, que el recurso de

18 Morón Urbina, Juan Carlos, Los recursos en la Ley del procedimiento administrativo general y en los procedimientos sectoriales, Gaceta Jurídica, Lima, 2009, p.46.

19 Esteve Pardo, José, Lecciones de Derecho Administrativo, Marcial Pons, Madrid, 2014, p. 237. 
reconsideración constituye una alternativa que se abre únicamente de manera previa a la vía del recurso de apelación. En otras palabras, una vez que se ha optado por acudir a la vía del recurso de apelación ya no es posible interponer, posteriormente, un recurso de reconsideración.

\subsection{Recurso de apelación}

A diferencia del recurso de reconsideración, el de apelación o jerárquico es un recurso que el administrado interpone para que sea resuelto por el órgano superior jerárquico de aquel que emitió la decisión objeto de cuestionamiento. Por ello se afirma que este recurso le permite al administrado que el objeto de la controversia sea conocido por un nuevo órgano que eventualmente pueda manifestar una opinión distinta a aquella expuesta por el órgano inicialmente encargado del procedimiento administrativo.

Sin embargo, debe tomarse en consideración que este recurso permite además favorecer el control interno de la Administración al mismo tiempo que expresa uno de los principios fundamentales de su organización como es el principio de jerarquía en la medida que permite que el órgano superior revise lo resuelto por el inferior. De este modo, la interposición del recurso de apelación, además de ser un instrumento útil en el ejercicio del derecho de defensa del administrado, activa el control institucional del que se dio cuenta líneas arriba.

Hace falta señalar también que, a diferencia del recurso de reconsideración, el de apelación se presenta como un recurso cuya interposición es preceptiva u obligatoria para agotar la vía administrativa. De manera que, salvo en los casos en los que el órgano que tome la decisión no se encuentre sujeto a jerarquía, nunca se podrá acudir a la vía del proceso contencioso administrativo si es que antes no se ha interpuesto en sede administrativa un recurso de apelación.

Finalmente, debemos señalar que el recurso de apelación solo puede ser interpuesto por única vez independientemente de cuantos superiores jerárquicos existan al interior de una institución. Esto es, el hecho de que el órgano que adoptó la decisión objeto de cuestionamiento se encuentre sometido a la jerarquía de otro órgano y este órgano, a su vez, se encuentre sujeto a jerarquía respecto de un tercer órgano, no determina que sea posible continuar con la interposición de distintos recursos de apelación hasta llegar al órgano superior jerárquico de toda la entidad, es decir, al titular de la misma.

\subsection{Recurso de revisión}

Finalmente, el tercer recurso regulado por la Ley No. 27444 es el de revisión. Se trata de un recurso excepcional que se puede plantear solo en un supuesto singular de acuerdo con los términos exigidos por el artículo $210^{\circ}$ de la referida ley. Y es que de su lectura se desprende que este recurso permite la activación de un tercer mecanismo de impugnación en aquellos supuestos en los que existan dos pronunciamientos que no hayan satisfecho el interés del administrado en instancias que no hayan tenido competencia de carácter nacional. 
De esta premisa puede deducirse que el recurso de revisión es una alternativa que surge en el marco de los procesos de descentralización territorial que, en casos como el peruano, determinan la existencia de organismos que no cuentan con competencia nacional sino únicamente con competencia local o regional. El fundamento que aparece, entonces, detrás de la regulación de este recurso es la necesidad de que el órgano de competencia nacional pueda convertirse en la instancia final o definitiva en determinado asunto en protección del administrado y con la finalidad de uniformizar los criterios que deberán seguir los órganos descentralizados sujetos a su tutela.

En cierta medida, nos encontramos nuevamente ante un recurso que tiene por finalidad también activar un control institucional, esta vez, desde el organismo nacional hacia los organismos descentralizados. $Y$ es que si bien estos órganos no se encuentran relacionados en función a un criterio de jerarquía sino más bien de tutela, el valor de la vocación por un Estado unitario busca que se extiendan mecanismos que favorezcan la uniformización de criterios entre estos órganos y el examen de un caso concreto puede convertirse en una herramienta útil para evaluar el sentido en el que los órganos regionales y locales vienen desarrollando sus funciones.

Ahora bien, el recurso de revisión debido a su naturaleza excepcional únicamente procede en los casos en los que una ley así lo establezca y siempre que se cumplan las condiciones previamente señaladas. En relación con su obligatoriedad, considerando la función de control institucional que cumple también este recurso, además de permitir el ejercicio del derecho de defensa por parte del administrado, debería considerarse que nos encontramos ante un recurso de interposición obligatoria para dar por agotada la vía administrativa ${ }^{20}$. Sin embargo, la ley no hace expresa referencia a esta regla y, por el contrario, es posible encontrarse con la regla general establecida en el artículo 218.2 de la LPAG que señala que el recurso de apelación es el que agota la vía administrativa como regla general.

En un caso como éste, una interpretación concordante con el debido procedimiento, debería significar que la definición sobre si el recurso de revisión resulta obligatorio o potestativo deberá ser resuelta por la legislación especial en cada caso particular y en los supuestos en los que la ley especial no establezca ningún criterio al respecto, deberá estimarse que resulta suficiente el recurso de apelación para dar por agotada la vía administrativa.

Finalmente, en relación con el ejercicio de todos estos recursos en general debemos señalar que, de acuerdo al mandato establecido en el artículo $214^{\circ}$ de la LPAG, solo pueden ser ejercidos única vez cada uno de ellos cuando corresponda y nunca pueden ser interpuestos de modo simultáneo.

20 En este sentido se pronuncia Espinosa-Saldaña Barrera, Eloy, Recursos administrativos: algunas consideraciones básicas y el análisis del tratamiento que les ha sido otorgado en la Ley No. 27444, en: AAVV, Comentarios a la Ley del Procedimiento Administrativo General, Ara Editores, Lima, 2003, p.448. 


\section{Trámite de los recursos administrativos}

En cuanto al procedimiento que debe desarrollar la entidad con la finalidad de dar trámite al recurso administrativo hay que decir, en primer lugar, que la interposición de cualquiera de los recursos antes referidos da lugar al inicio de un nuevo procedimiento administrativo. La doctrina ${ }^{21}$ suele hacer esta precisión para especificar con razón que no nos encontramos ante la continuación del procedimiento administrativo que dio origen al acto objeto de impugnación o ante una etapa de mera revisión formal de la decisión adoptada previamente, sino que, por el contrario, nos encontramos ante un procedimiento administrativo nuevo y autónomo.

Una aclaración en este sentido tiene importantes consecuencias. Entre otras cosas, permite dar fundamento a la facultad que tiene el administrado de presentar nuevas pruebas o alegar nuevos hechos durante todo el desarrollo del procedimiento de impugnación. No hay un límite en la ley que establezca nada al respecto, razón por la cual es válido concluir que el administrado puede hacer nuevas alegaciones en el procedimiento de impugnación sin necesidad de tener que sujetarse o someterse a los argumentos esbozados en la instancia ordinaria que conoció el procedimiento. Tal vez el único límite lo constituya la buena fe y la correcta conducta procedimental a la que están siempre sujetos tanto la autoridad administrativa como el administrado.

Inclusive, si, en el caso de un procedimiento administrativo sancionador, la prescripción de la infracción no fuera alegada durante el desarrollo del procedimiento en la instancia ordinaria, no existe ningún obstáculo para que el administrado alegue la prescripción por vía de defensa en el marco del procedimiento impugnativo. Se trata de una prueba más de que la tutela del derecho de defensa y la concepción del procedimiento de impugnación como un procedimiento autónomo permiten negar su identificación con una simple instancia de revisión formal ${ }^{22}$.

En esa misma línea, debe tenerse en cuenta también que al tratarse de un nuevo procedimiento $y$, en definitiva, de un procedimiento administrativo más, resultarán

21 En este sentido se pronuncia la mayoría de la doctrina. Entre otros, puede verse al respecto: Parejo Alfonso, Luciano, Lecciones de Derecho Administrativo, Tirant Lo Blanch, Valencia, 2013, p. 635; Ruiz de Apodaca, Ángel. Los recursos en el derecho administrativo: fundamento y aproximación a los sistemas español y peruano, Normas Legales, Trujillo, 2006, p. 8; y Rodríguez-Arana, Jaime y Sendín, Miguel Ángel, Derecho Administrativo Español, Editorial Netbiblo, Tomo II, La Coruña, 2009, p. 290. En sede nacional son de la misma opinión Morón Urbina, Juan Carlos, Los recursos en la Ley del procedimiento administrativo general y en los procedimientos sectoriales, Gaceta Jurídica, Lima, 2009, p. 10; y Martin Tirado, Richard, Los recursos administrativos y el control difuso en la Administración Pública, en: Revista de Derecho Administrativo, Círculo de Derecho Administrativo-CDA, Lima, 2010, p.218 227. 
aplicables para su trámite todas las normas dispuestas antes del capítulo relacionado a los recursos administrativos de la ley, en la medida que le resulten aplicables.

Ahora bien, el procedimiento que se inicia con la interposición del recurso administrativo tiene lugar con la sola presentación del mismo a través del órgano de recepción documental correspondiente cumpliendo con todas las exigencias formales que son requeridas por ley. En ese sentido, no se requiere en sede administrativa, a diferencia de lo que sucede muchas veces en sede judicial, el dictado de un auto "concesorio" o de una resolución que declare admitido a trámite el recurso administrativo. Si se configurara el incumplimiento de algún requisito formal, la autoridad diligente otorgará un plazo razonable para la subsanación correspondiente por parte del administrado. Por el contrario, en caso el recurso cumpla con todas las exigencias formales exigidas por ley, automáticamente se dará trámite al mismo, sin que la Administración se encuentre obligada a emitir un pronunciamiento expreso a favor de la admisibilidad del instrumento de impugnación. Una regla en este sentido, indudablemente, se sustenta en el principio de informalismo y en el carácter expeditivo que debe tener este procedimiento.

Por otro lado, debe tomarse en cuenta que en el momento de la interposición del recurso administrativo, se abre la posibilidad de que la autoridad administrativa determine si se deben suspender o no los efectos y la ejecución del acto impugnado. Sobre el particular, el artículo $216^{\circ}$ de la LPAG ha establecido, como regla general, que la sola interposición de un recurso administrativo no obliga a la autoridad administrativa a resolver la suspensión de los efectos del acto impugnado. Por el contrario, ésta será una decisión que le corresponderá adoptar a la Administración de acuerdo con las circunstancias específicas que rodean al caso. Para ello, el legislador ha establecido un marco legal dentro del cual debe moverse la discrecionalidad con la que la autoridad administrativa actúa en estos casos. En ese sentido, el mismo artículo ha referido que la entidad podrá disponer la suspensión de los efectos del acto impugnado únicamente en los casos en los que se configure alguna de las siguientes circunstancias: (i) Cuando la ejecución del acto impugnado pueda causar perjuicios de imposible o difícil reparación o (ii) Cuando se aprecie objetivamente la existencia de un vicio de nulidad trascendente.

Al respecto, debemos señalar que, a diferencia de lo que sucede en sede judicial, la declaración de suspensión de efectos de un acto impugnado termina siendo verdaderamente infrecuente. $Y$ es que no puede perderse de vista que sobre el acto impugnado pesa una presunción legal importante como es el caso de la presunción de validez expresamente reconocida por el artículo $9^{\circ}$ de la Ley del Procedimiento Administrativo General. Más aún, si se toma en cuenta que es la propia entidad la encargada de resolver la suspensión, y en el caso del recurso de reconsideración inclusive el mismo órgano que emitió la decisión ahora cuestionada, no existen muchos incentivos para que la autoridad desconfíe a priori de la validez de su propia decisión. 
Si bien las probabilidades de que la autoridad administrativa adopte de oficio la decisión de suspender los efectos del acto impugnado terminan siendo las mismas, y por las mismas razones, lo cierto es que cuando el administrado alegue la configuración de alguno de los dos supuestos previstos por el legislador para autorizar la suspensión, la autoridad administrativa se encontrará obligada al examen de las circunstancias del caso para determinar si la referida suspensión debería proceder o no.

El primero de los supuestos en los que podría proceder la suspensión de la ejecución del acto impugnado se presenta cuando la ejecución del mismo podría causar perjuicios de imposible o difícil reparación. Este supuesto, evidentemente, busca que la autoridad administrativa evalúe si la ejecución inmediata del acto impugnado podría causar al administrado, o al interés público, un daño irremediable o difícilmente reparable. Si este fuera el caso, es evidente que una resolución que declare posteriormente la nulidad del acto impugnado podría terminar resultando inoportuna o inservible. Este supuesto se encuentra directamente relacionado con la idea del peligro en la demora, razón por la cual se reconoce a la suspensión de efectos del acto impugnado como una de las medidas provisionales por excelencia que la Administración se encuentra en aptitud de dictar.

Un caso que debería exigir la suspensión de la ejecución del acto impugnado por esta causal podría presentarse, por ejemplo, en el supuesto de algunas autorizaciones ambientales. Así, a modo de ejemplo, frente a una autorización de desbosque impugnada por un administrado que considera que ésta no procede porque el espacio sobre el cual se ha solicitado la autorización constituye un área natural protegida, lo prudente podría ser determinar la suspensión de los efectos del acto cuestionado. De lo contrario, es decir, de permitirse el desbosque mientras dura el trámite del procedimiento de impugnación, una eventual resolución fundada del recurso administrativo terminaría siendo inservible.

Lo mismo podría suceder en el caso en el que un administrado impugna una medida provisional desproporcionada por la autoridad administrativa que podría generar perjuicios de imposible reparación como el impedimento de un administrado para participar en determinado concurso público. En un caso como éste corresponde también que la Administración evalúe si es que corresponde o no suspender los efectos a través de un ejercicio de ponderación.

El segundo supuesto viene dado por lo que el legislador ha denominado la apreciación objetiva de un vicio de nulidad trascendente. A diferencia de otros ordenamientos que regulan la figura de la anulabilidad en el caso peruano los vicios de nulidad pueden conducir únicamente a su nulidad o a su conservación en caso se trate de supuestos subsanables. En este sentido, estimaríamos que esta causal estaría haciendo referencia a los supuestos en los que nos encontramos ante vicios de nulidad no conservables. Aun de acuerdo con esta interpretación, consideramos que puede ser un exceso estimar que ante cualquier supuesto de nulidad no conservable la autoridad 
administrativa tiene el deber de evaluar la suspensión de los efectos del acto impugnado. Además, de tratarse de una interpretación muy lejana de lo que sucedería en la realidad, lo cierto es que con esta causal así entendida prácticamente se desnaturalizaría la protección de presunción de validez que pesa sobre el acto administrativo, ya que en la práctica cualquier alegación de existencia de un vicio de nulidad la Administración estaría obligada a evaluar la procedencia de la suspensión de efectos de un acto que todavía no se sabe realmente inválido.

Por esta razón, consideramos que, en realidad, una interpretación razonable de este principio obligaría a pensar que la propuesta del legislador en este supuesto sería la de un vicio de nulidad evidente o manifiesto. Es decir, que ante la evidencia de que la Administración ha incurrido en un vicio de nulidad como podría ser, por ejemplo, la contravención expresa a una norma legal vigente, se podría considerar la suspensión de la ejecución del acto administrativo cuestionado.

En realidad, y nuevamente derivado de la naturaleza cautelar de la suspensión de los efectos del acto impugnado, el elemento más importante a considerar también en este supuesto, y además de la existencia de un vicio de nulidad manifiesto, es el peligro en la demora que debe acompañar a la situación y demandar la actuación de la Administración para suspender los efectos de su decisión provisionalmente ${ }^{23}$.

Por lo demás, vale la pena resaltar que en cualquier caso la determinación de la suspensión de la ejecución del acto impugnado constituye un supuesto de ejercicio discrecional, de tal manera que aun cuando se materialice alguno de los dos supuestos habilitadores de la suspensión de efectos del acto impugnado, la Administración puede encontrar buenas razones que justifiquen no adoptar la decisión de suspender sus efectos. $\mathrm{Y}$ es que, indudablemente, la decisión de suspensión de los efectos demandará un ejercicio de ponderación relevante que debe llevar a cabo la autoridad administrativa y que puede tener como resultado distintas conclusiones en función a las circunstancias específicas de cada procedimiento.

Se trata, en realidad, de una exigencia de doble ponderación ${ }^{24}$ en la medida que la Administración deberá evaluar, de un lado, los problemas que le podría causar al recurrente la no suspensión de los efectos del acto impugnado pero, al mismo tiempo, deberá evaluar los problemas que la suspensión de la ejecución del acto cuestionado le podría causar al interés público o a los derechos de terceros administrados. Así, por ejemplo, en el caso de la impugnación del otorgamiento de la buena pro en el marco de un proceso de selección, si evalúa la decisión de suspender la ejecución del acto impugnado, la Administración se encuentra obligada a ponderar cuáles son los perjuicios que causaría al recurrente la no suspensión de la ejecución impugnada pero

23 Sánchez Morón, Miguel, Derecho Administrativo. Parte General, Tecnos, Octava edición, Madrid, 2012, p. 839. 235. 
al mismo tiempo deberá evaluar los perjuicios que se podrían causar a la persona que resultó ganadora de la buena pro o a la propia entidad contratante en caso se determine la suspensión de efectos (la demora en la suscripción y ejecución del contrato, por ejemplo).

Quizás porque este ejercicio de ponderación siempre supondrá el sacrificio en mayor o menor medida de algún bien merecedor de tutela, el propio artículo $216^{\circ}$ de la LPAG reconoce la potestad de la entidad de adoptar medidas que sean necesarias para asegurar la protección del interés público y de los derechos de terceros, cuando la Administración resuelva suspender la ejecución del acto impugnado. En otras palabras, si se opta por la suspensión, cabe la adopción de otras medidas cautelares complementarias que busquen tutelar el interés público que pretendía satisfacer el acto suspendido o los derechos de terceros ${ }^{25}$.

Para concluir con la regulación de la suspensión de los efectos del acto impugnado, debemos señalar que, a diferencia de otros ordenamientos que no lo regulan así expresamente, la Ley del Procedimiento Administrativo General ha dispuesto que en el caso de los procedimientos administrativo sancionadores la regla general será distinta a aquella que regula los supuestos ordinarios. Así, en caso nos encontremos frente a la impugnación de un acto de sanción, la regulación ordena que el acto solo podrá ser ejecutado cuando haya quedado firme, es decir, cuando no proceda ningún recurso administrativo contra él. Y es que en un supuesto como éste la presunción de validez que recubre al acto administrativo parece ceder frente a la presunción de licitud de la que gozan los actos del administrado.

Hay que decir, ahora, que la fase de instrucción que tiene lugar en el caso del procedimiento impugnativo es normalmente reducida en la medida que la información requerida para resolver la controversia surgida en este procedimiento se extrae básicamente de aquel otro que dio origen al acto objeto de impugnación. Como ha quedado dicho, no existe ningún tipo de limitación para que, dentro del respeto al debido procedimiento, la entidad o el administrado aporten nuevas pruebas o aleguen nuevos hechos dirigidos a resolver la controversia o incertidumbre generada con la interposición del recurso administrativo. Sin embargo, se trata de un supuesto que se podrá generar en función a las circunstancias particulares del caso y que no necesariamente debe ocurrir. En caso no ocurra, la fase de instrucción estará dedicada al análisis e interpretación de las pruebas y alegaciones formuladas en el procedimiento desarrollado por la instancia ordinaria, así como de la compatibilidad de la resolución impugnada con el marco legal vigente.

Por supuesto, en el caso en el que la autoridad administrativa, debido a diferentes circunstancias, alegue nuevos hechos o introduzca nuevos medios probatorios no contenidos en el expediente del procedimiento seguido ante la instancia ordinaria, ésta

25 Parejo Alfonso, Luciano, Lecciones de Derecho Administrativo, Tirant Lo Blanch, Valencia, 2013, p. 641. 
deberá permitir que el administrado ejerza su derecho de defensa al respecto de forma escrita o de forma oral a través de la celebración de una audiencia ${ }^{26}$. Evidentemente, nos referimos a los supuestos vinculados directamente con las alegaciones formuladas en el procedimiento. Si fuera el caso que la autoridad administrativa va a hacer uso de un nuevo razonamiento jurídico para evaluar los hechos del caso, ésta no se encuentra obligada a dárselos a conocer al administrado sino hasta la resolución del recurso administrativo.

El segundo caso en el que la autoridad administrativa se verá obligada a dar audiencia durante el procedimiento impugnativo es aquél en el que hubiera otros interesados en el asunto además del recurrente, es decir, otros administrados cuyos derechos o intereses legítimos podrían resultar afectados a partir de la decisión que se adopte en la resolución del recurso. Evidentemente, nos referimos a aquellos administrados interesados que la entidad se encuentre en capacidad de conocer en virtud del propio expediente o por otros medios. A ellos corresponde otorgarles un plazo razonable para que presenten sus descargos respecto de lo planteado en el recurso por parte del recurrente corriéndoles traslado del mismo ${ }^{27}$.

Una vez culminada la etapa de instrucción de este procedimiento el órgano encargado de resolver el recurso administrativo se encuentra listo para elaborar la resolución que, eventualmente, pondrá fin al procedimiento impugnativo. Arribados a esta parte, tal vez lo último que resta decir es que, de acuerdo con el artículo $67^{\circ}$ de la ley la potestad de resolver recursos administrativos no puede ser delegada. Se busca con esto evitar cualquier afectación al debido procedimiento del administrado quien siempre deberá saber que quien resolverá su recurso administrativo será aquél órgano previamente determinado por ley.

\section{Resolución del recurso administrativo}

La decisión a través de la cual se resuelve el recurso administrativo interpuesto podrá declarar fundada la impugnación del administrado o desestimar la misma declarándola infundada. El recurso también podrá ser declarado fundado cuando la Administración estime solo una parte de lo solicitado por el administrado a través de la impugnación. Conviene señalar, además, que cuando la Administración declare fundado el recurso administrativo interpuesto usualmente lo hará por las razones que habrá expuesto el recurrente durante el procedimiento impugnativo pero, por cierto, nada obsta para que en caso la autoridad administrativa, en su proceso de análisis, encuentre otros fundamentos que ameriten la anulación del acto cuestionado, pueda hacer uso de ellos. La única restricción, como señalamos líneas arriba, ocurre en el supuesto en el que la Administración haga uso de nuevas pruebas o nuevas alegaciones para perjudicar al administrado en cuyo caso se requerirá que, antes de resolver de acuerdo

26 Entrena Cuesta, Rafael, Curso de Derecho Administrativo, Décimo tercera edición, Tecnos, Madrid, 1999, p. 279.

27

Sánchez Morón, Miguel, Derecho Administrativo. Parte General, Tecnos, Octava edición, Madrid, 2012, p. 841. 
con estas consideraciones, las ponga en conocimiento del recurrente para que éste exprese lo que crea conveniente al respecto.

Debe señalarse también que el recurso podrá declararse fundado o infundado por razones de forma o de fondo. Así, podrá declararse infundado por razones formales cuando, por ejemplo, no se hayan respetado las reglas del debido procedimiento o, por razones de fondo cuando, por ejemplo, el recurrente efectivamente logre acreditar que cuenta con los requisitos para acceder a una licencia o un permiso que le ha sido denegado a través del acto impugnado. En ambos supuestos, la autoridad administrativa se encuentra facultada para resolver sobre el fondo del asunto. Esto sucederá en el caso del recurso que es fundado por razones formales, cuando la autoridad administrativa cuente con los elementos de juicio suficientes para resolver sobre el fondo. Si este supuesto no se configurara, corresponderá que la Administración ordene la retrotracción del procedimiento hasta el momento en el que se cometió el vicio de nulidad y ordenará al órgano encargado que retome el trámite del procedimiento desde esa etapa.

En este último caso, conviene precisar que la resolución que ordene la retrotracción en el supuesto en el que se determine la existencia de un vicio formal en el desarrollo del procedimiento ordinario deberá hacerlo únicamente cuando se considere que este vicio formal pudo haber afectado directamente la decisión que se adoptó sobre el fondo ${ }^{28}$. De lo contrario, en caso se ordene retrotraer el procedimiento por un vicio formal que existió pero no fue relevante para el sentido de la decisión final, se ordenaría la subsanación para luego de la corrección llegar a una resolución en el mismo sentido y frente a la cual, eventualmente, el administrado impondría nuevamente un recurso administrativo. Un ejercicio en este sentido, indudablemente, atentaría contra los principios de celeridad y eficacia que regulan el procedimiento administrativo en nuestro ordenamiento.

Por supuesto, en ambos casos, cuando el recurso se estime o desestime por razones de fondo o de forma, la autoridad administrativa estará obligada a motivar correctamente su decisión. Ésta no es sino una consecuencia derivada del artículo $3^{\circ}$ de la Ley según el cual todo acto administrativo tiene entre sus elementos de validez una debida motivación. $Y$, como es evidente, la resolución que pone fin al procedimiento de impugnación no constituye otra cosa que un acto administrativo.

En definitiva, el acto que resuelva el recurso interpuesto deberá referirse a todos los hechos planteados por el administrado en el acto de impugnación y en todas las oportunidades que haya tenido para presentar alegaciones. Del mismo modo, deberá articular correctamente una serie de hechos y argumentos jurídicos con la finalidad de evidenciar las razones por las cuales estima o desestima el recurso administrativo. Madrid, 2012, p. 841. 
Evidentemente, como sucede en cualquier solicitud presentada por un administrado, la Administración se encontrará limitada por el principio de congruencia al momento de resolver de manera tal que no podrá resolver más allá de lo solicitado por el administrado a menos que se lo haga saber a tiempo y le permita ejercer su derecho de defensa sobre el particular. En el caso del procedimiento administrativo sancionador esta regla de congruencia presenta una singularidad que viene dada por el principio de prohibición de reforma en peor según el cual no es posible que, en el caso en el que el recurrente haya impugnado una sanción, al momento de resolver, la Administración pueda imponerle una sanción mayor a aquella que el administrado cuestionó inicialmente. Se trata de una regla que busca proteger el derecho de defensa del administrado y que rechaza cualquier tipo de desincentivo para que pueda hacer uso de los recursos administrativos que tiene a disposición por parte del ordenamiento.

Pero todas estas consideraciones deberán tomarse en cuenta en los supuestos en los que la autoridad administrativa proceda diligentemente y resuelva expresamente el recurso administrativo interpuesto. Sin embargo, existe también la posibilidad de que, por diferentes razones, la Administración no cumpla con resolver el recurso interpuesto dentro del plazo de treinta días hábiles previsto desde la legislación general. En ese caso la ley ha previsto la configuración de un supuesto de silencio administrativo positivo en los supuestos en los que la resolución de primera instancia hubiera denegado lo solicitado y la configuración de un supuesto de silencio administrativo negativo en los demás casos.

En este último supuesto, en caso opere el silencio administrativo negativo merece la pena señalar que, aun cuando la ley no lo establezca expresamente, no se puede iniciar el cómputo de plazos para la interposición de un segundo recurso administrativo o para acudir a la jurisdicción contencioso administrativa. Es decir, el momento en el que se configura el silencio administrativo negativo por la falta de pronunciamiento de la Administración no determina el inicio del cómputo de ningún plazo que pueda perjudicar al administrado. $Y$ es que se entiende que si bien existen plazos perentorios para la interposición de recursos administrativos o para acudir al proceso contencioso administrativo, en éstos casos, iniciar el cómputo del plazo supondría validar un acto posiblemente ilegal por la sola desidia de la Administración ${ }^{29}$.

Otras formas alternativas de terminar con el procedimiento recursivo, aun cuando la ley no lo señale expresamente para el caso del procedimiento recursivo, podrían ser el desistimiento $o$ un acuerdo convencional entre las partes enfrentadas, en el caso de un procedimiento trilateral. Como se sabe, la normativa general y especial permite en muchos casos el desistimiento de la pretensión o del propio procedimiento y el acuerdo entre los administrados para solucionar un problema, siempre que sea aprobado por la autoridad administrativa y sin perjuicio de que ella pueda decidir continuar con el

29 De Asís Roig, Agustín, Los recursos administrativos de reposición y de alzada. En: Revista Documentación Administrativa No. 254-255, Mayo-Diciembre, INAP, Madrid, 1999, p. 315. 
procedimiento debido al interés público que pueda encontrar en el objeto del procedimiento.

Finalmente, debemos señalar que en los supuestos en los que la resolución decida sobre un recurso de reconsideración, el administrado, en caso de no encontrarse satisfecho con el resultado obtenido contará con nuevos quince (15) días hábiles para interponer un recurso de apelación, si existiera un superior jerárquico ante quien recurrir. Si, por el contrario, este órgano no se encontrara sujeto a jerarquía se entenderá agotada la vía administrativa y el administrado podrá acudir al proceso contencioso administrativo de no encontrarse satisfecho. En el supuesto en el que se resuelva un recurso de apelación, la referida resolución determinará el agotamiento de la vía administrativa salvo que nos encontremos ante el supuesto en el que podría proceder un recurso de revisión.

\section{Conclusiones}

Como se puede apreciar, existe una regulación adecuada de los recursos administrativos por parte de la Ley del Procedimiento Administrativo General, aun cuando consideramos que existen supuestos perfectibles o que requerirían una aclaración expresa por parte del legislador con la finalidad de evitar poner en riesgo el cumplimiento de las distintas funciones que ostentan los mecanismos de impugnación en sede administrativa.

Un supuesto que merecería particular atención y que no ha sido contemplado en el marco legal vigente estaría referido a aquellos casos en los que, después de que un acto ha quedado consentido, algún hecho nuevo y posterior logra confirmar que el acto incurre en una causal de nulidad y que debería ser dejado sin efectos. La norma no ha previsto qué es lo que sucede en estos casos. Si bien la Administración cuenta con la herramienta de la nulidad de oficio para los casos en los que solo hayan transcurrido de uno a tres años para poder anular la decisión en sede administrativa o en sede judicial, lo cierto es que no se ha dotado al administrado de ninguna herramienta para reclamar la nulidad de un acto que se creía válido pero que ahora, debido a la aparición de nuevos hechos, se comprueba nulo. Por lo demás, en la medida que nuestro ordenamiento sujeta a la nulidad de oficio a un plazo de caducidad, tampoco se sabe qué herramienta se podría utilizar de comprobarse la nulidad del acto después del cumplimiento de ese plazo.

No consideramos correcto permitir que un acto nulo se convalide por el solo hecho de que hayan transcurrido más de tres años desde su consentimiento en cuyo caso ni siquiera la Administración podrá pretender su nulidad de oficio. Tampoco parece tuitivo que no existan instrumentos para que un administrado cuestione una decisión cuya nulidad, por alguna razón específica, recién pudo probarse después de transcurrido los breves plazos que el administrado tiene para impugnar. Por esta razón, tal vez habría que contemplar un supuesto excepcional de manera que el administrado cuente con herramientas de actuación en casos como éste y que, un incorrecto respaldo en el 
principio de seguridad jurídica, puede hacer creer que el referido acto merece ser convalidado a sabiendas de su nulidad.

Dentro de estos casos, por supuesto, también se encuentran las situaciones en las que se termine declarando mediante sentencia judicial firme la falsedad de alguna declaración o documento que haya servido directamente para justificar el dictado de un acto administrativo. En estos supuestos nos encontraríamos claramente ante una causal de nulidad derivada de la infracción penal pero, si nos encontráramos dentro del periodo en el que la administración puede ejercer su potestad nulificante de oficio, el administrado estaría sujeto a que la entidad haga uso de la misma sin contar con ninguna herramienta para exigirle que declare la nulidad de aquél acto, más allá de una simple petición de gracia. 